\title{
Impact of Roadside Friction on Travel Speed and LOS of Rural Highways in India
}

\author{
Sudipta Pal $^{1} \cdot$ Sudip Kr Roy ${ }^{2}$
}

Received: 7 November 2015/Accepted: 19 February 2016/Published online: 28 April 2016

(c) Springer International Publishing Switzerland 2016

\begin{abstract}
Substantial amount of money has been invested by Government of India and several State Governments to improve the level of service of various categories of roads in India. Roads have been widened and strengthened, surface condition has been improved but Level of Service has not been improved as expected because of various socioeconomic factors. One of the important factors has been the presence of side friction along Indian rural highways. Existence of road-side markets at regular interval along rural highways is very common in India. These market areas act as pseudo bottleneck points and confusion zones to the through traffic of highways. Interaction among fast moving vehicles, pedestrian and non-motorized local vehicles is very unique phenomenon. Literature review reveals that not much work has been carried out to understand impact of side friction on travel speed and Level of Service. An attempt has been made in the present work to quantify the impact of roadside friction on travel speed and LOS of Indian rural highways. Based on data collected from three study sections, speed-flow curves were developed for various side friction levels and five threshold values for LOS are suggested considering operational speed and freedom of maneuver as measure of effectiveness.
\end{abstract}

Sudipta Pal

spalonline@rediffmail.com

Sudip Kr Roy

sudip33172@gmail.com

1 RITES Ltd, Highway Division Kolkata, 56 CR Avenue, Kolkata, West Bengal 700012, India

2 Department of Civil Engineering, IIEST, Shibpur, Howrah, West Bengal 711103, India
Keywords Friction element - Roadside friction index · Travel speed $\cdot$ Level of service

\section{Introduction}

In spite of widening and strengthening of existing roads prevailing Level of Service has not been improved as expected in many rural highways in India because of several socio-economic factors and prevailing land use pattern. Existence of road side markets at regular interval along rural highways is very common in India. These market areas act as pseudo bottleneck points and confusion zones to the through traffic of highways. In the present study, efforts has been made to quantify impact of side friction on travel speed and LOS of Indian rural highways. Mid block sections of three rural highways adjacent to Kolkata were selected as study sections. In market areas, presence of pedestrians, cycles and van-rikshaws on carriageway considered as friction elements creating resistance for through traffic movements. Classified traffic volume data, spot speed and friction data i.e., numbers of friction elements on the carriageway were collected during field survey by trained enumerator. Speed-flow graphs were developed for both outside and within market area scenario. Level of service (LOS) criterions were suggested and impact of side friction was investigated. Outcome of the study will help policy makers to take decisions regarding strict imposition of laws to restrict development of such road side market areas and create more provisions for service roads and offstreet market places.

Literature review reveals that little work has been done till date for quantification of side friction and its impact on travel speed and LOS. Some of the relevant work in Indian scenario which dealt with LOS and capacity were reviewed for the 
present study. A work [1] deals with adjustment factors and thereby evaluating capacity of two-lane road under mixed traffic condition is reviewed for the present work. In this paper six parameters are considered for capacity estimation i.e., lane width, shoulder condition, roughness, directional split, terrain condition, percentage of slow moving vehicles. In another study, [2] level of congestion was quantified and then used it as a measure of level of Service (LOS). Five level of services designated by the letters A-E have been proposed. In a work [3] it was shown that variation of PCU values will be useful to pick an appropriate PCU value for the different types of vehicles in mixed traffic streams based on the observed composition of the vehicles in the stream. In a paper [4] Neural Network (NN) was used for capturing the underlying non-linear effects of traffic volume and its composition level on the stream speed. It was found that PCE of a vehicle type varies in a non-linear manner with total traffic volume and compositional share of that vehicle type in the traffic stream. In a work [5]. Heterosim simulation model was used to estimate pcu factors for heterogeneous traffic for wide range of upgrades. It was demonstrated that PCU value of a vehicle significantly changes with change in traffic volume, magnitude of upgrade and its length. In a paper [6] regression curves were analyzed based on four classical models: Greenshields, Greenberg, Underwood, and Bellshape models and compared using data collected from Beijing Third Ring Road (BTRR) and Jing Jin Tang Highway (JJTH) in China. In a paper [7] a new term stream equivalency factor (SEF) was introduced and denoted by $\mathrm{K}$. It is the ratio of traffic volume in PCU per hour and volume in vehicles per hour. The $\mathrm{K}$ factor is related to traffic composition and volume on a road through the regression analysis method.

\section{Study Sections}

In this study field data have been collected from three project roads. Bakrahat Road, Basanti Highway and MG Road are important rural highway and sub-arterial standard road of South Suburban area of Kolkata and South 24 pargana district of West Bengal, India. Traffic is highly heterogeneous in nature in all three study roads. Various roadside business activities like vegetable/fish market and grocery shops exist along study roads. The details of selected road sections are given in Table 1.

Three mid block sections were selected along the above roads. Study sections were selected in such a way that there was no major intersection within the stretch. There were a numerous variations of road side activities within the study stretch. Traffic flow was heterogeneous in nature. One section was having semi-urban characteristics and other two sections belonged to rural highway category. Three study stretches were selected such a manner so that speed, volume and side friction data could be obtained with a wide range of variation. Locations of three study corridors have been marked on Google map and shown in Fig. 1.

\section{Methodology}

Methodology adopted for the present study for various field data collection and analysis are described under following broad heads.

\section{Data Collection}

All field data were collected in pre-designed format by trained enumerators under supervision of the authors. Traffic volume and extent of side friction varies among three study roads. As all three study sections were of twolane standard carriageway and traffic has been heterogeneous, collected data have been compiled together to develop relation of speed, flow and side friction.

\section{Traffic Data}

Classified traffic volume count was carried out by trained enumerator using standard format of IRC SP19-2001 [8] in study stretch sufficiently away from market area. Traffic survey carried out from 6.00 am to 11.00 am i.e., covering peak market hours. It was observed that traffic composition in study sections was highly heterogeneous with substantial amount of slow moving vehicles like Bicycle, Rikshaw and Van-Rikshaw. Compositions of typical hourly traffic in three study stretches are shown below in Fig. 2.

As traffic data collected during market hours only, Average Daily Traffic (ADT) volume could not be obtained. However, variation of hourly traffic volume in three study sections is shown in Fig. 3. It was observed that prevailing traffic volume was much higher in MG road w.r.t other two study sections.

\section{Friction Data}

During market hours number of pedestrians, cycles and rickshaw vans carrying various vegetable and other goods move randomly on carriageway. Their random movements affect smooth flow of fast moving traffic even when traffic volume was low. In the present study, roadside friction was expressed in terms of the number of elements like pedestrian, cycle and rickshaw-van standing on the carriageway or crossing the carriageway. Time duration for this survey was 
Table 1 Details of study sections

\begin{tabular}{lllllll}
\hline $\begin{array}{l}\text { S1. } \\
\text { no. }\end{array}$ & $\begin{array}{l}\text { Name of } \\
\text { the road }\end{array}$ & Study stretch & Type of road & Name of market area & $\begin{array}{l}\text { Length of study } \\
\text { section }\end{array}$ & $\begin{array}{l}\text { Length of } \\
\text { market area }\end{array}$ \\
\hline 1 & $\begin{array}{c}\text { Bakrahat } \\
\text { Road }\end{array}$ & $\begin{array}{c}\text { PBS business school to Dream } \\
\text { Institute of Technology }\end{array}$ & $\begin{array}{c}\text { 2-Lane (rural } \\
\text { highway) }\end{array}$ & Shamali Market area & $2.5 \mathrm{~km}$ & $400 \mathrm{~m}$ \\
2 & $\begin{array}{c}\text { Basanti } \\
\text { Highway }\end{array}$ & $\begin{array}{c}\text { Near Ghusighata and Bamunpukur } \\
\text { Bazar }\end{array}$ & $\begin{array}{c}\text { 2-lane (rural } \\
\text { highway) }\end{array}$ & $\begin{array}{c}\text { Ghusighata and } \\
\text { Bamanpukur market area }\end{array}$ & $4.8 \mathrm{~km}$ & 300 and $200 \mathrm{~m}$ \\
MG Road & $\begin{array}{c}\text { Karunamayee bridge-Kabardanga jn } \\
\text { of "MG Road" }\end{array}$ & $\begin{array}{c}\text { 2-lane (semi- } \\
\text { urban road) }\end{array}$ & Keorapukur Market area & $2.4 \mathrm{~km}$ & $600 \mathrm{~m}$ \\
\hline
\end{tabular}

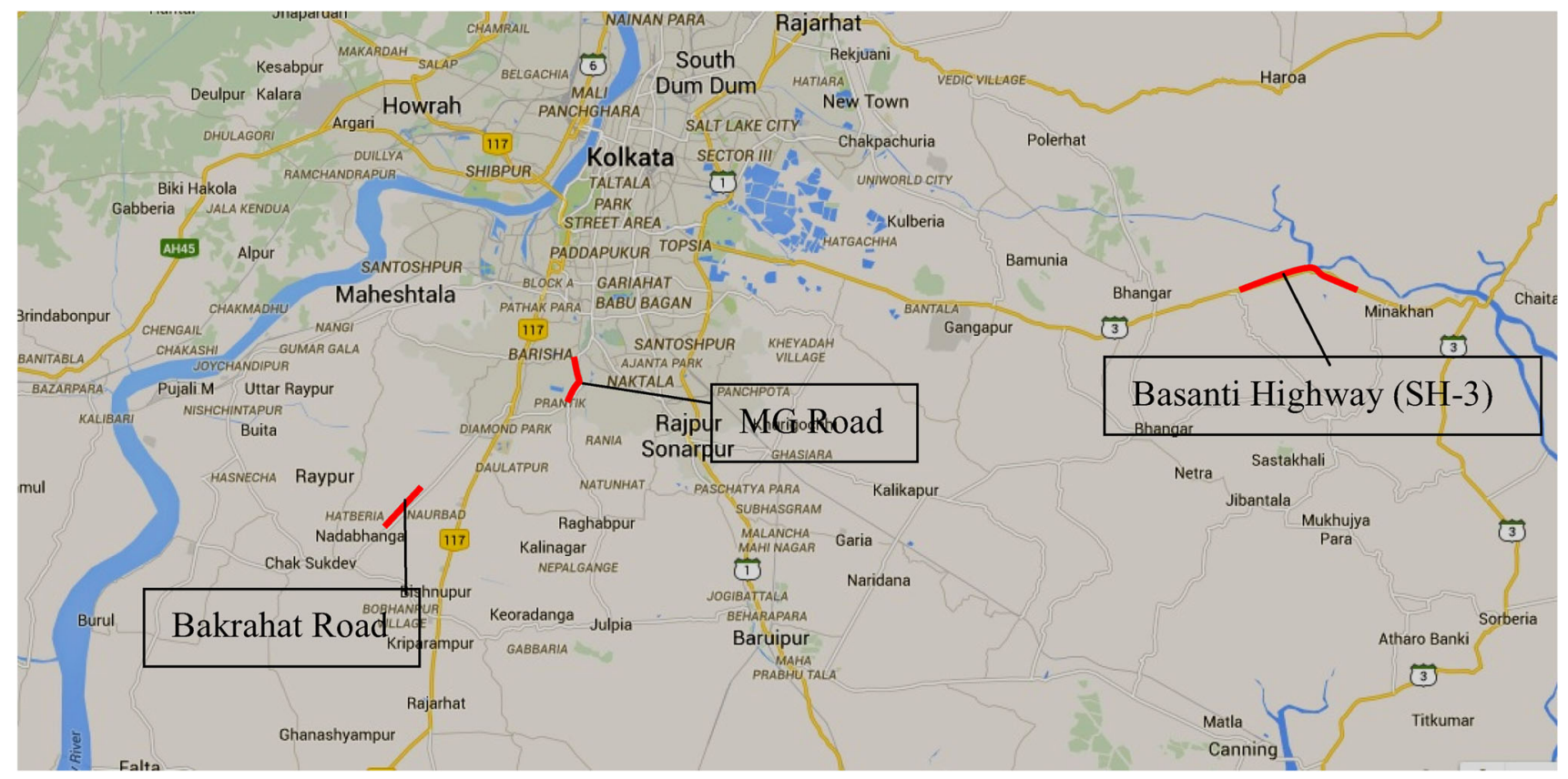

Fig. 1 Key map showing Study Sections

from $6.00 \mathrm{am}$ to $11.00 \mathrm{am}$ for each study stretch. The continuous video photography was carried out from an elevated point within market area focusing camera on carriageway.

Carriageway was divided into three strips in longitudinal direction for a representative length of $100 \mathrm{~m}$. It was observed during repeated field visits that number of friction elements varies across the cross section of the road in market areas. Number is more near carriageway edge and it gradually decreases towards centre of carriageway. One meter strip on either edge of the carriageway considered as edge strip and middle strip consists of remaining part of the carriageway. Width of strips was decided after repeated site visits and close observation of movement of friction elements across the carriageway. This concept is explained in Fig. 4. One set of friction data was collected for each $5 \mathrm{~min}$ interval. Video photographic data were observed repeatedly and trained enumerators counted number of friction elements present on middle and edge strip of carriageway for each $5 \mathrm{~min}$ interval for a particular instance at random.
This typical data were considered as representative friction data of respective $5 \mathrm{~min}$.

\section{Speed Data}

To understand variation of travel speed within and outside the market area of study stretch, two sets of spot speed data were collected using 'radar gun'. One set of data was collected within market area while another set of data was collected outside the market area. Three spot speed readings were obtained for each $5 \mathrm{~min}$ intervals at random. Different types of vehicles were targeted to represent heterogeneity in speed data. Average of three values was considered as representative spot speed of that $5 \mathrm{~min}$ time period. Therefore, total sample size of spot speed data collected during market hours $(6.00 \mathrm{am}$ to $11.00 \mathrm{am})$ from each study stretch is $360(2 \times 3 \times 12 \times 5)$ for both inside and outside the market area. 


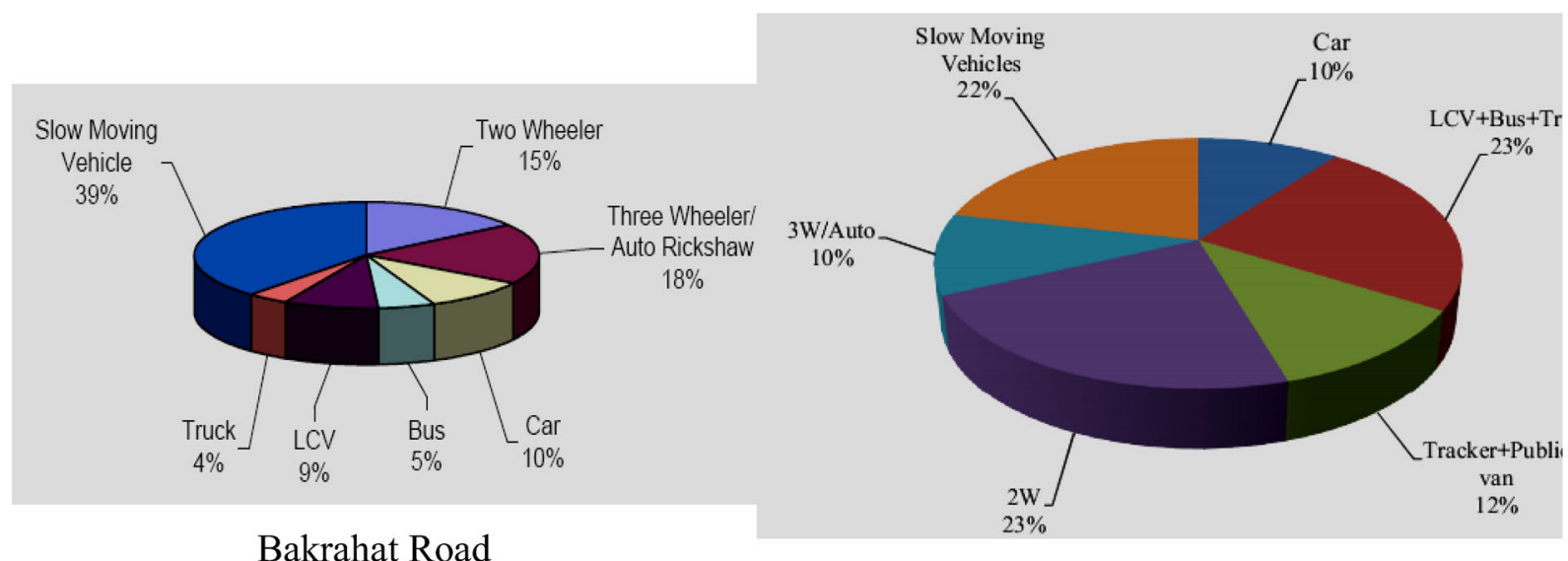

Bakrahat Road

Basanti Highway

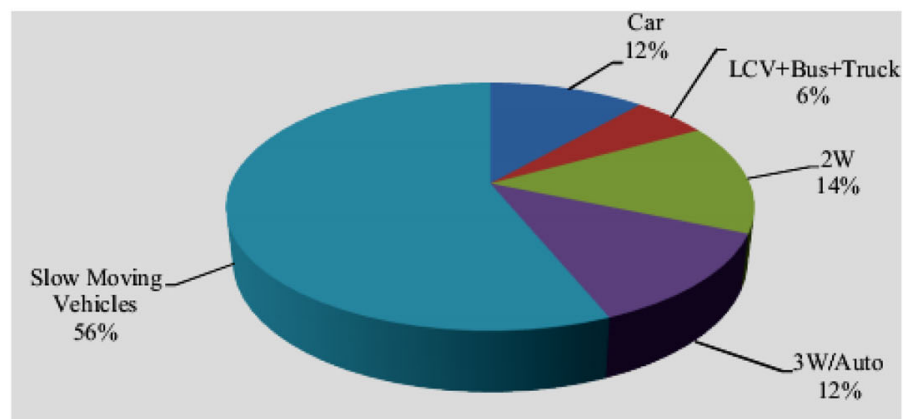

MG Road

Fig. 2 Traffic composition of typical hourly flow on study stretches

Fig. 3 Variation of hourly traffic flow on three study stretches

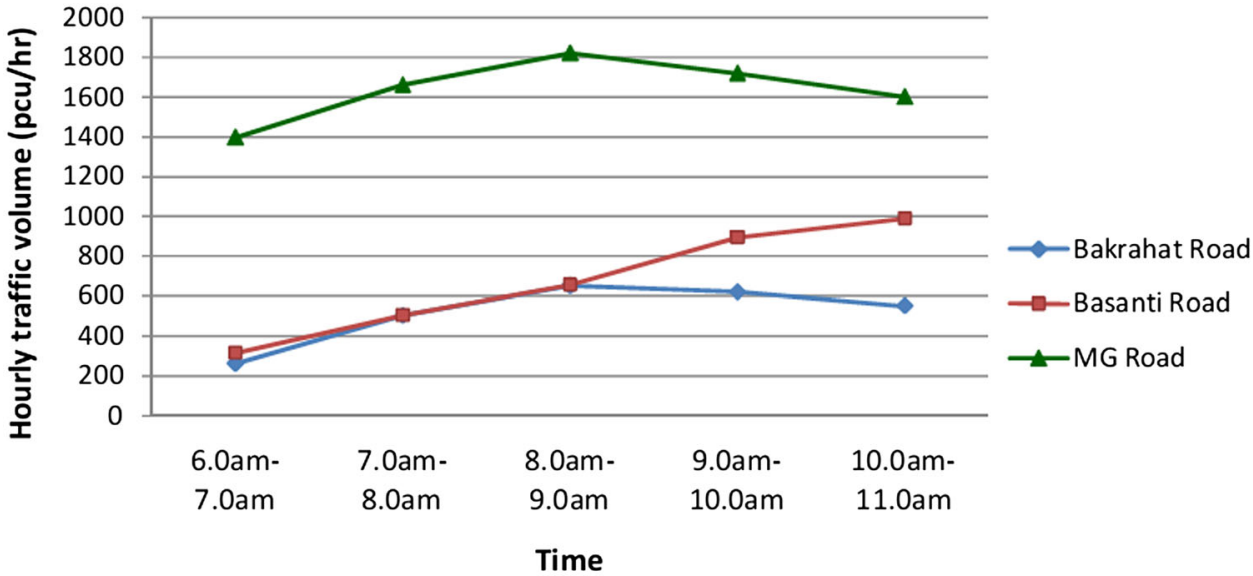

\section{Estimation of Road Side Friction Index (RSFI)}

Various friction elements have different impacts on travel speed based on their static and dynamic characteristics and their position on the carriageway. An index namely "road side friction index" has been proposed to quantify the side friction. Number of friction elements in the form of pedestrian, cycles and van-rickshaws standing or crossing the carriageway present within $100 \mathrm{~m}$ stretch have been multiplied by a weight factor to estimate a 'road side friction index' (RSFI) for that particular instance.

Various friction elements will have different impact on through traffic based on their physical dimension and position on carriageway. For example a van rickshaw on the middle of carriageway will certainly have larger impact to travel speed in comparison with a pedestrian standing on $0.5 \mathrm{~m}$ inside of carriageway edge. The concept of weight factor was developed to assign different weight to each friction element based 
Fig. 4 Details of edge and middle strip marked on carriageway

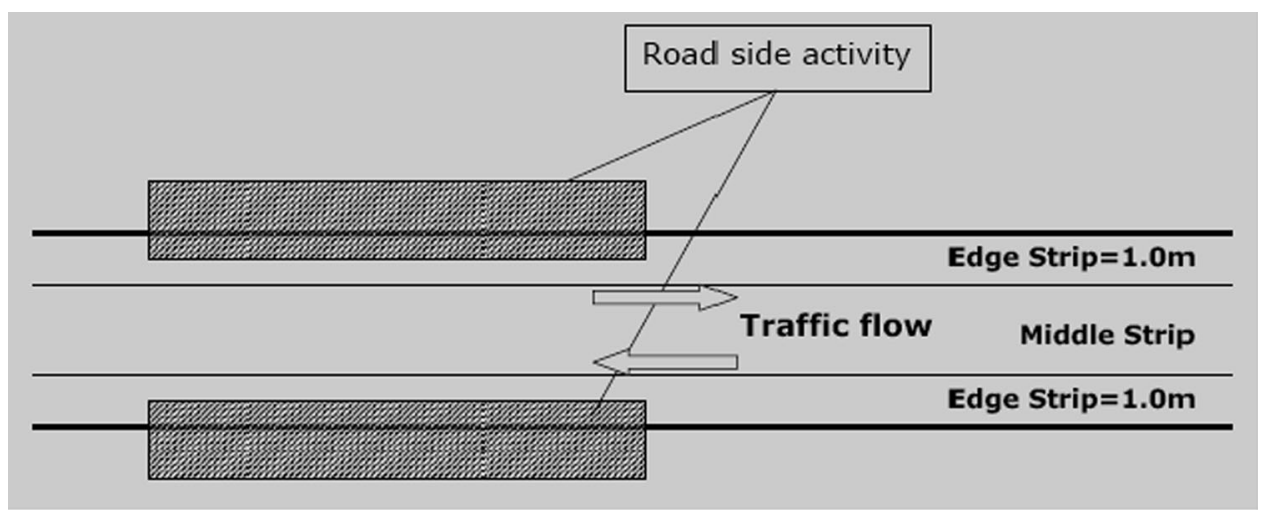

on their contribution towards disturbance to through traffic. Weight factors were calculated based on projected area of respective friction element and their distance from carriageway edge. Impact of Side Friction was considered as combined effect of physical dimension of friction element and their position on carriageway. In case of vehicular traffic, passenger car considered as unit and other type of vehicles converted to passenger car by multiplying pcu factors as per various codal guidelines. Similarly, in the present study, pedestrian standing on carriageway edge strip considered as unit of side friction. Area effect was estimated as ratio of projected area of a particular type of friction element and pedestrian which is referred as area ratio (AR). The disturbance to through traffic also depends on the position of friction element on carriageway. This effect was estimated as ratio of distance of particular midpoint of strip from carriageway edge on which friction element currently standing to midpoint of edge strip and presented as distance ratio (DR). For example, distance ratio (DR) of a friction element standing on middle strip of a two-lane $(7.0 \mathrm{~m})$ carriageway $=($ distance of midpoint of middle strip from carriageway edge)/(distance of midpoint of edge strip from carriageway edge) $=3.5$ / $0.5=7.0$. Friction elements crossing the carriageway obviously have maximum impact as they are equally disturbing up and down traffic while crossing $7.0 \mathrm{~m}$ width of carriageway. It was assumed that friction elements cross carriageway perpendicularly. Estimation of Weight Factors is summarized below in Table 2. Finally weight factors were scaled considering pedestrian standing on edge strip as unit of side friction. Values of scaled weight factors are shown in Table 3.

A typical observed data for side friction parameter and calculation of RSFI is shown below in Table 4.

\section{Development of Speed-Flow Curves}

To study the variation of the speed profile with operating volume, speed-flow curves were developed. Speed and traffic volume data were collected for each 5 min interval. Spot speed data were converted to space mean speed using standard relationship between time mean speed (TMS) and space mean speed (SMS). Density values were calculated from speed-flow data using fundamental relationship among traffic parameters $($ speed $=$ flow $\times$ density). As three study sections have similarity in terms of carriageway width $(7.0 \mathrm{~m})$, alignment (straight), traffic composition and pavement surface condition, data collected from three study sections were compiled together and speed-density curves were developed to establish the relationship of observed data and compare with basic models of Greenfield and Greenberg. Based on equation obtained from best fit lines of speed density curves and fundamental relationships speed flow values were estimated [6]. Two set of speed-flow curves were developed, one representing operating condition outside the market area while other represents condition within market area. During literature review it was observed that no specific methods were advised to determine dynamic pcu in presence of side friction. Therefore, static PCU factors as per IRC-64 1990 [9] have been considered for the present study.

\section{Level of Service of Rural Highways}

Unique characteristic of traffic flow in two-lane highways is that passing maneuvers takes place in the gaps available within the moving vehicles of opposing lane. As traffic volume in opposing direction as well as geometric restriction increases passing opportunity decreases. Based on wide range of functions served by two-lane highways, Highway Capacity Manual (HCM) 2010 [10] classified two-lane highways into three classes. First two classes represent rural highways while third class represents roads in developed areas. As per US HCM, m ost arterial roads and trunk roads are considered to be class-I highway while most collector and local roads considered to be class-II and III highways. In HCM-2010 three measures of effectiveness are considered i.e., average travel speed (ATS), percent time spent following (PTSF) and percent of free flow speed (PFFS). 
Table 2 Details of weight factor estimated for study roads

\begin{tabular}{|c|c|c|c|c|c|c|}
\hline \multirow{2}{*}{$\begin{array}{l}\text { S1. } \\
\text { no. }\end{array}$} & \multirow{2}{*}{$\begin{array}{l}\text { Details of friction } \\
\text { elements }\end{array}$} & \multirow[t]{2}{*}{ Projected area $A_{i}(\mathrm{sqm})$} & \multicolumn{4}{|l|}{ Edge strip $=1.0 \mathrm{~m}$} \\
\hline & & & $\begin{array}{l}\text { distance of cw edge from } \\
\text { stip mid point } d_{i}(m) d_{e}\end{array}$ & $\begin{array}{l}\text { Area ratio } \\
A R=A_{i} / A_{p}\end{array}$ & $\begin{array}{l}\text { Distance ratio } \\
\mathrm{DR}=\mathrm{d}_{\mathrm{i}} / \mathrm{d}_{\mathrm{e}}\end{array}$ & $\begin{array}{l}\text { Weight factor } \\
\left(\mathrm{W}_{\mathrm{i}}\right)=\mathrm{AR}+\mathrm{DR}\end{array}$ \\
\hline 1 & Pedestrian & 0.50 & 0.5 & 1.00 & 1.00 & 2.00 \\
\hline 2 & Cycle & 0.86 & 0.5 & 1.72 & 1.00 & 2.72 \\
\hline 3 & Rickshaw van & 2.56 & $\begin{array}{l}0.5 \\
\text { Middle strip }=5.0 \mathrm{~m} \\
\mathrm{~d}_{\mathrm{m}}\end{array}$ & 5.12 & $\begin{array}{r}1.00 \\
\mathrm{~d}_{\mathrm{m}} / \mathrm{d}_{\mathrm{e}}\end{array}$ & 6.12 \\
\hline 1 & Pedestrian & 0.50 & 3.5 & 1.00 & 7.00 & 8.00 \\
\hline 2 & Cycle & 0.86 & 3.5 & 1.72 & 7.00 & 8.72 \\
\hline 3 & Rickshaw van & 2.56 & $\begin{array}{l}3.5 \\
\text { Crossing }=7.0 \mathrm{~m} \\
\mathrm{~d}_{\mathrm{c}}\end{array}$ & 5.12 & 7.00 & 12.12 \\
\hline 1 & Pedestrian & 0.50 & 7.0 & 1.00 & 14.00 & 15.00 \\
\hline 2 & Cycle & 0.86 & 7.0 & 1.72 & 14.00 & 15.72 \\
\hline 3 & Rickshaw van & 2.56 & 7.0 & 5.12 & 14.00 & 19.12 \\
\hline
\end{tabular}

$d_{i}$ distance of ith friction element from carriageway edge, $A_{i}$ projected area of ith friction element, Road side friction index $(\mathrm{RSFI})=\sum \mathrm{n}_{\mathrm{i}} \mathrm{W}_{\mathrm{i}}$, $R S F I$ roadside friction index, $n_{i}$ number of ith type friction elements in $100 \mathrm{~m}$ stretch, $W_{i}$ weightage factor for i type side friction parameter

Table 3 Scaled weight factors considering pedestrian on edge strip as unit

\begin{tabular}{lllll}
\hline & & Edge strip & Middle strip & Crossing \\
\hline 1 & Pedestrian & 1.00 & 4.00 & 7.50 \\
2 & Cycle & 1.36 & 4.36 & 7.86 \\
3 & Rickshaw van & 3.06 & 6.06 & 9.56 \\
\hline
\end{tabular}

Present study deals with impact of side friction on travel speed and LOS of Indian two-lane rural highways. Passing opportunity decreases with traffic volume. It further reduces within market area due to presence of friction elements on carriageway. In the present study two measures of effectiveness are proposed for defining LOS criteria i.e., operational speed and standard deviation of spot speeds. In a two-lane highway where traffic is heterogeneous, fast moving vehicles always search for passing opportunity for overtaking slow moving vehicles to maintain their desired travel speed. Therefore, standard deviation of spot speeds represents prevailing overtaking opportunity within traffic stream. It is high within heterogeneous traffic stream where passing opportunity is more. With limited passing opportunity standard deviation reduces. Operational speed i.e., 85th percentile speed is representative of prevailing operating condition and mobility within a traffic stream. Average free flow speeds (FFS) on study sections were measured during early morning (5.30 am) when traffic volume was very low and there were no road side activities. Average value of FFS was found to be $70 \mathrm{~km} / \mathrm{hr}$ in study stretches. Speed profiles, speed flow curves were developed using the data obtained from three study sections. These were examined thoroughly and following threshold values of LOS are recommended.

\section{Data Analysis and Interpretation}

The field data have been compiled in excel format to develop speed-density curves.

Table 4 Typical calculation of RSFI

\begin{tabular}{|c|c|c|c|c|c|c|c|c|c|c|c|c|c|}
\hline \multirow[t]{3}{*}{ Time } & \multicolumn{12}{|c|}{ Average number of friction element } & \multirow[t]{3}{*}{ RSFI } \\
\hline & \multicolumn{3}{|c|}{ Left edge strip } & \multicolumn{3}{|c|}{ Middle strip } & \multicolumn{3}{|c|}{ Right edge strip } & \multicolumn{3}{|l|}{ Crossing } & \\
\hline & Pedestrian & Cycle & $\begin{array}{l}\text { Van } \\
\text { rikshaw }\end{array}$ & Pedestrian & Cycle & $\begin{array}{l}\text { Van } \\
\text { rikshaw }\end{array}$ & Pedestrian & Cycle & $\begin{array}{l}\text { Van } \\
\text { rikshaw }\end{array}$ & Pedestrian & Cycle & $\begin{array}{l}\text { Van } \\
\text { rikshaw }\end{array}$ & \\
\hline $\mathrm{WF} \rightarrow$ & 1.0 & 1.36 & 3.06 & 4.00 & 4.36 & 6.06 & 1.0 & 1.36 & 3.06 & 7.50 & 7.86 & 9.56 & 87.50 \\
\hline $\begin{array}{l}7.00 \mathrm{am} \\
\text { to } 7.15 \\
\mathrm{am}\end{array}$ & 11 & 3 & 1 & 2 & 1 & 1 & 8 & 11 & 1 & 1 & 1 & 1 & \\
\hline
\end{tabular}




\section{Development of Speed Flow Curves}

Two sets of speed-density curves were developed representing flow conditions outside and within market area using field data collected from three study sections. Two speed-density curves are shown for outside and within market condition in Figs. 5 and 6 respectively. Best fit lines following straight line and logarithm relations were tried to model the relation. It is observed that Greenberg model i.e., logarithmic relationship have higher $\mathrm{R}^{2}$ value (0.9339).

It was observed (Fig. 6) that the best fit line (Greenberg model) have low $\mathrm{R}^{2}$ value due to the presence of friction elements on carriageway.

Using the speed-density equation obtained from Fig. 5 representative flow values for each $5 \mathrm{~min}$ interval were estimated using fundamental relationship i.e., flow $=$ speed $\times$ density. Speed-flow curves thus developed for outside market area are shown in Fig. 7.

In case of within market area scenario, speed and density data were thoroughly examined and grouped into three categories based on extent of road side activities after repeated trials. Three categories represented side friction level as low, medium and severe with RSFI values less than 40,40 to 60 and greater than 60 respectively. Grouped speed-density curves were plotted and shown in Fig. 8. It was observed that $\mathrm{R}^{2}$ values for classified speed-density curves were much higher than single curve. In two cases logarithmic relationship and for third case exponential relationship was found to be best fitted. Three speed-flow curves were plotted for three side friction levels within market area. Speed-FLOW curves were developed using equations of basic relationship among speed, flow and density. Speed-flow curves developed for various side friction levels within market area is shown in Fig. 9. It was observed that speed-flow curve shifted vertically downwards with increase of side friction level even traffic volume was same.

\section{Impact of Side Friction}

To study impact of side friction on travel speed difference between spot speed within and outside market area was calculated for each $5 \mathrm{~min}$ interval. Percentage speed
Fig. 5 Speed vs density curve for area outside the market

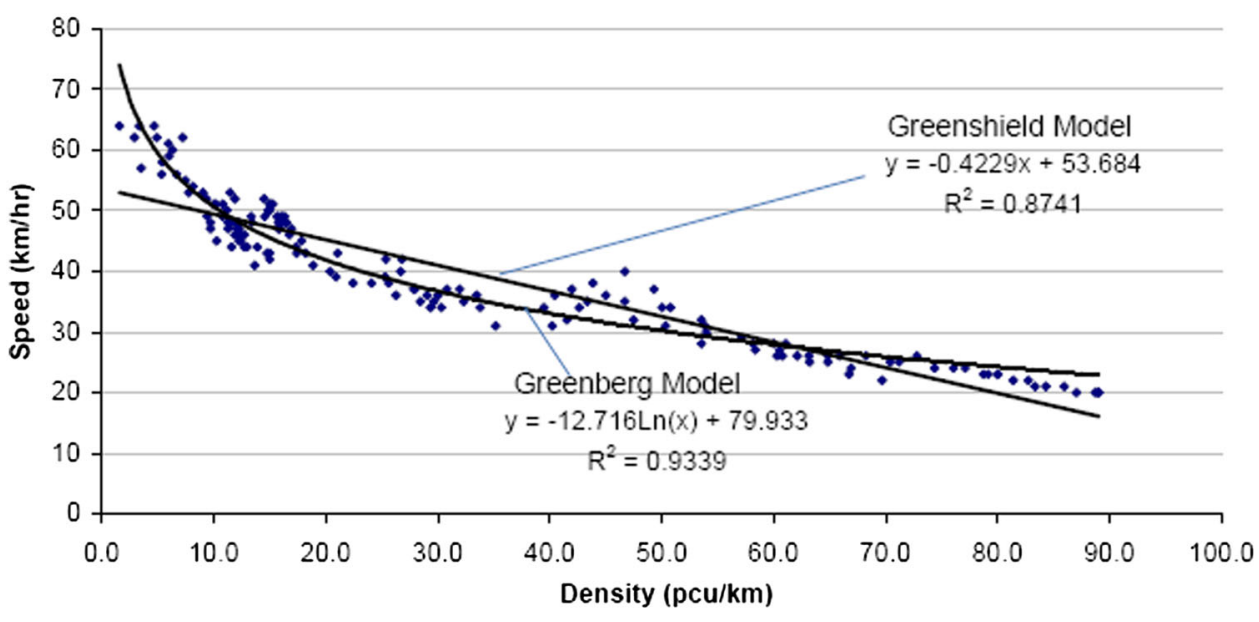

Fig. 6 Speed vs density curve for area within the market

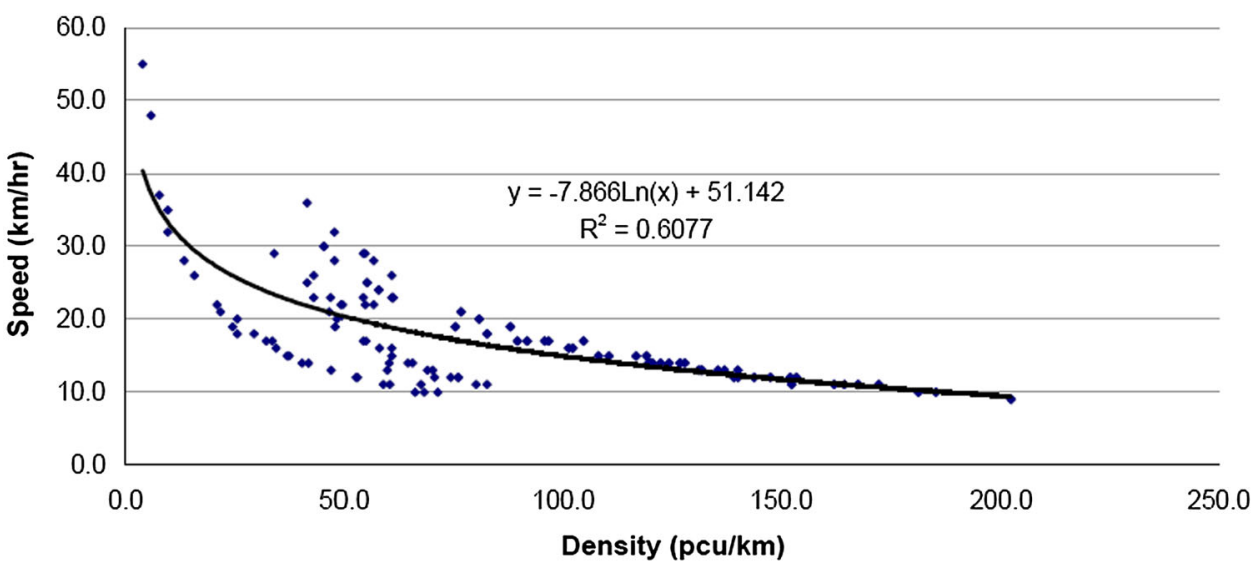


Fig. 7 Speed-flow curve for area out side the market

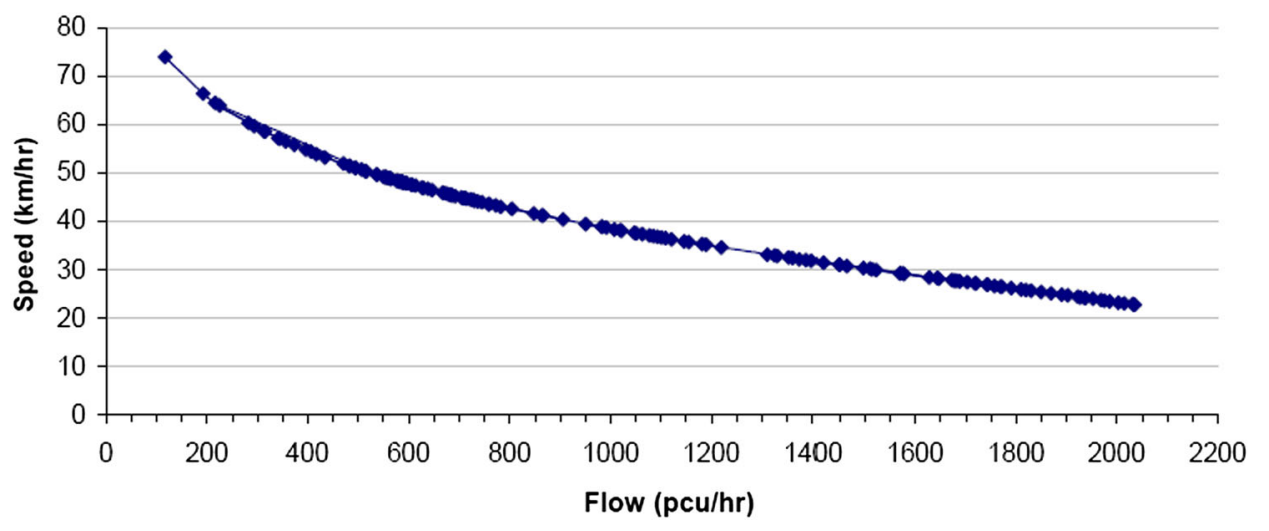

reduction within market area w.r.t outside market area was calculated and plotted against corresponding RSFI. It was observed in Fig. 10 that for initial values of RSFI speed reduced rapidly and beyond certain level $(\mathrm{RSFI}=40)$ speed reduced in much lower rate with increase of RSFI.

This was because of the presence of friction elements on the carriageway. With increase of side friction speed of the fast moving vehicles reduced drastically within market area and compelled to follow a platoon type movement. Further increase in friction level or traffic volume have lower impact on travel speed as same was already came down to a lower level.

Impact of side friction also depended on the level of traffic volume plying through the road. In a very low traffic volume impact of side friction was less while at higher flow level when speed was already at lower level w.r.t free flow speed impact of side friction was more. At higher traffic volume level even slight increase in side friction will have severe impact on opportunity of overtaking manoeuvrability resulting decrease in travel speed. To study the impact of side friction on different level of traffic volume, basic data base for Fig. 10 were further clustered into three traffic volume levels and plotted again (Fig. 11). It was observed that slope of graph was much steeper at higher traffic volume level in comparison to that of lower volume. However, for all traffic volume, rate of speed reduction was more for initial values of RSFI. Beyond certain limit $(\mathrm{RSFI}=45)$ rate of speed reduction reduced. This relationship is shown in Fig. 11.

\section{Impact on Travel Speed}

In this study operational speed i.e., 85th percentile speed was considered as measure of effectiveness while defining LOS. Cumulative speed graphs were developed for both within and outside market area and superimposed in Fig. 12. It was observed that operational speed was much restricted within market area and value was estimated to be $25 \mathrm{~km} / \mathrm{hr}$ while that of outside market area was $50 \mathrm{~km} / \mathrm{hr}$. Therefore, operational speed reduced $50 \%$ within market area in comparison to outside area due to side friction effect.

\section{Impact on LOS}

It is already mentioned that operational speed and standard deviation of spot speed were considered as measure of effectiveness for defining LOS. Operational speed represented mobility in the traffic stream while standard deviation of spot speeds indicated opportunity for overtaking within traffic stream under heterogeneous traffic condition. In a heterogeneous traffic stream plying on two lane carriageway, fast moving vehicles always tries to overtake slow moving vehicles ahead whenever opportunity of overtaking comes. This help fast moving vehicles to maintain their desired speed and LOS.

Five LOS were suggested in the present work after thorough review of results of data analysis. Average free flow speed was measured in the field before 6.00 am and found to be $70 \mathrm{~km} / \mathrm{hr}$. Suggested threshold values are already indicated in Table 5. Two speed flow curves representing operating condition within and outside market scenario are shown in Figs. 13 and 14 in which LOS regions have been marked. It was observed that speed flow curves within market area were restricted within lower speed region. Even for low traffic volume prevailing LOS within market area are D and E because of less mobility and lower scope of overtaking opportunity.

Impact of side friction in terms of operational speed and standard deviation of spot speeds and corresponding LOS are summarized in Table 6. Standard deviation of spot speeds decreased with increase of RSFI values representing less passing opportunity within traffic stream. 
Fig. 8 Classified speed-density curves based on side friction level
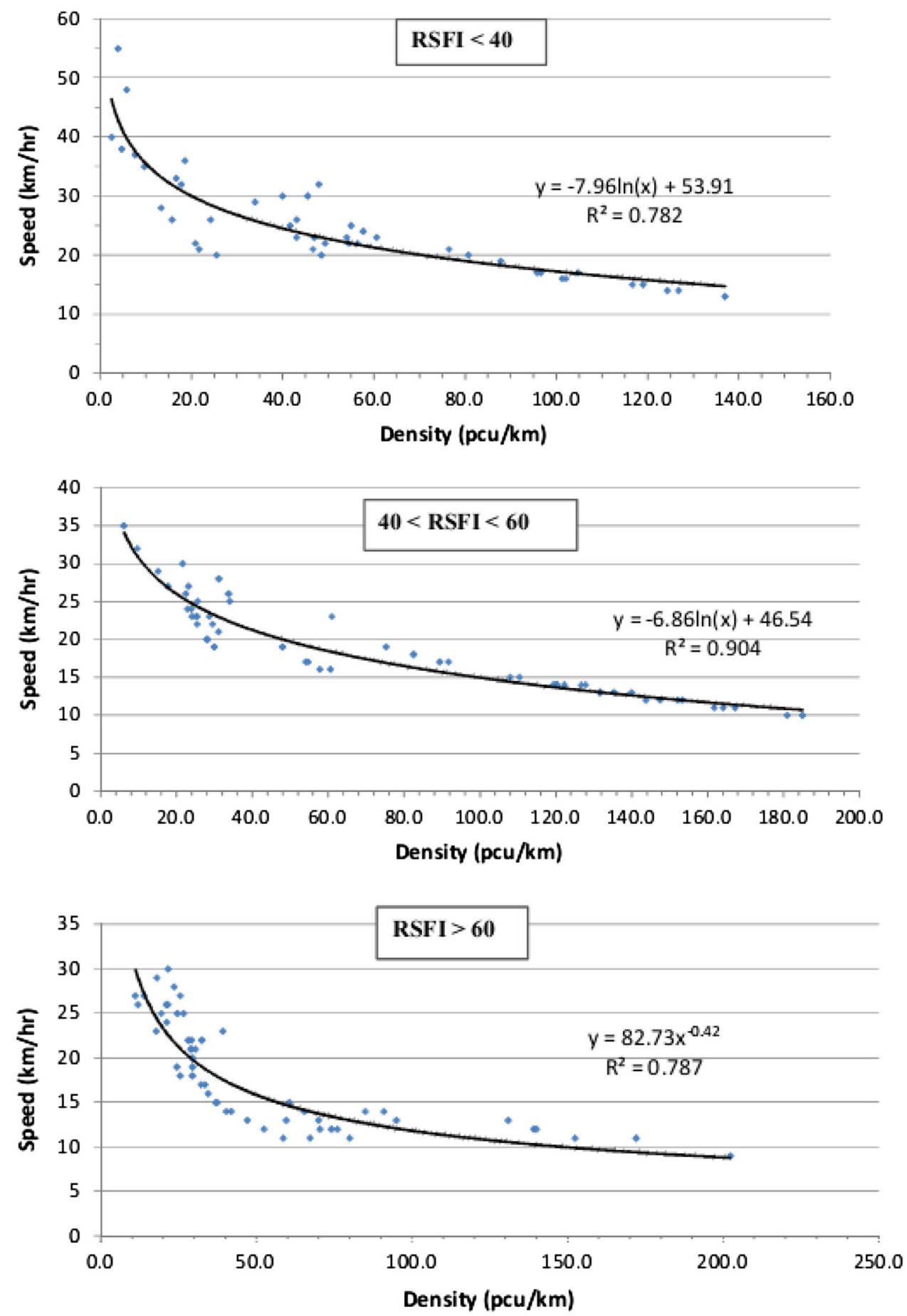

\section{Conclusions}

Ribbon development along highways and side friction are common phenomenon in developing countries like India. In the present study a methodology has been demonstrated to quantify roadside friction considering projected area and position of friction elements on carriageway. Impact on travel speed has been quantified and speed flow curves have been developed for different side friction levels. The criteria for five LOS have been recommended considering operational speed and scope of overtaking maneuverability as measure of effectiveness. LOS threshold values further classified into three levels of side frictions within market area. Methodology has been demonstrated with the help of 
Fig. 9 Speed-flow curves for area within the market

Fig. 10 Speed-flow curves for area within the market

Fig. 11 Speed-flow curves within the market at different traffic volume level
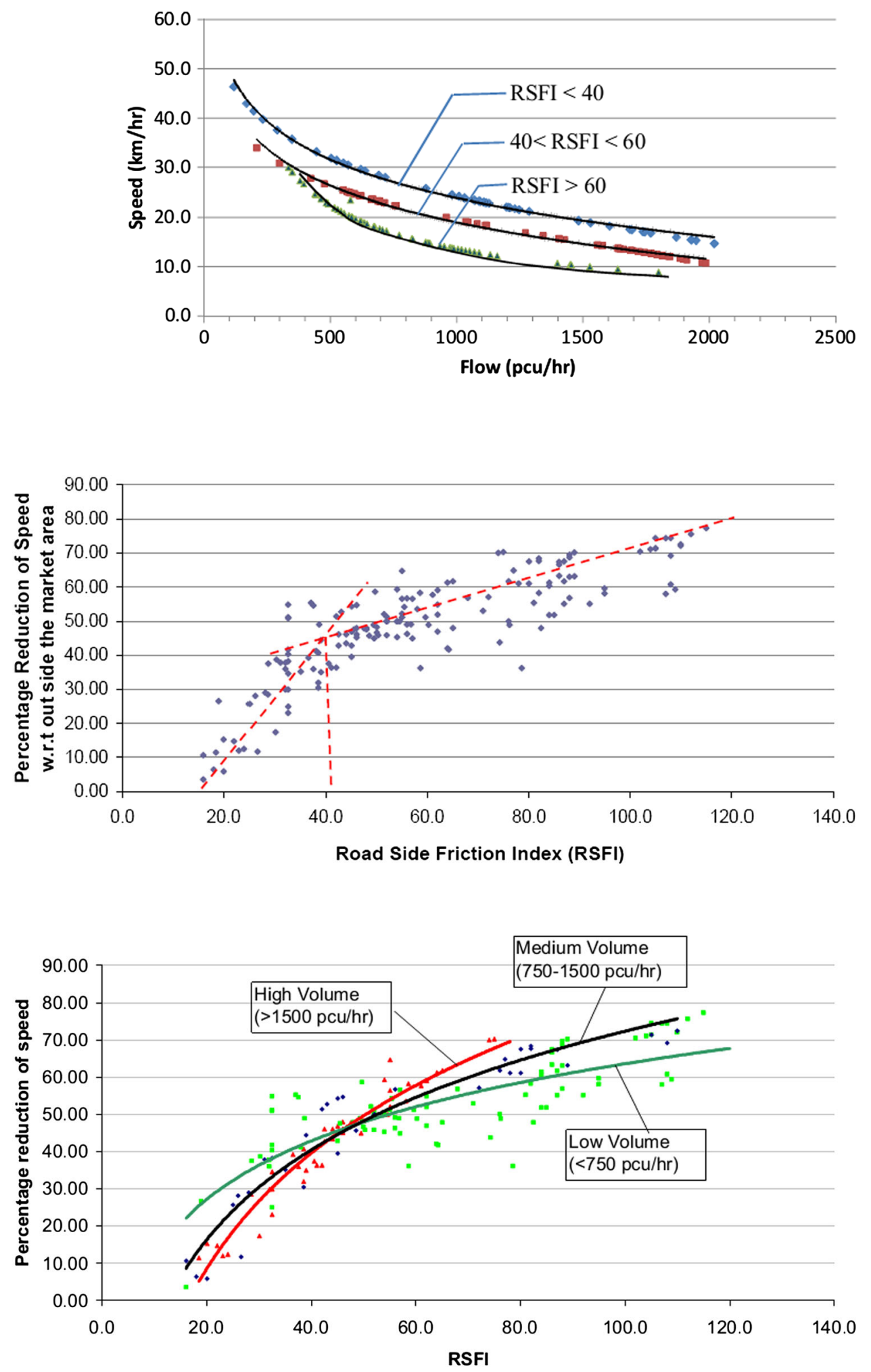
Fig. 12 Cumulative speed graph

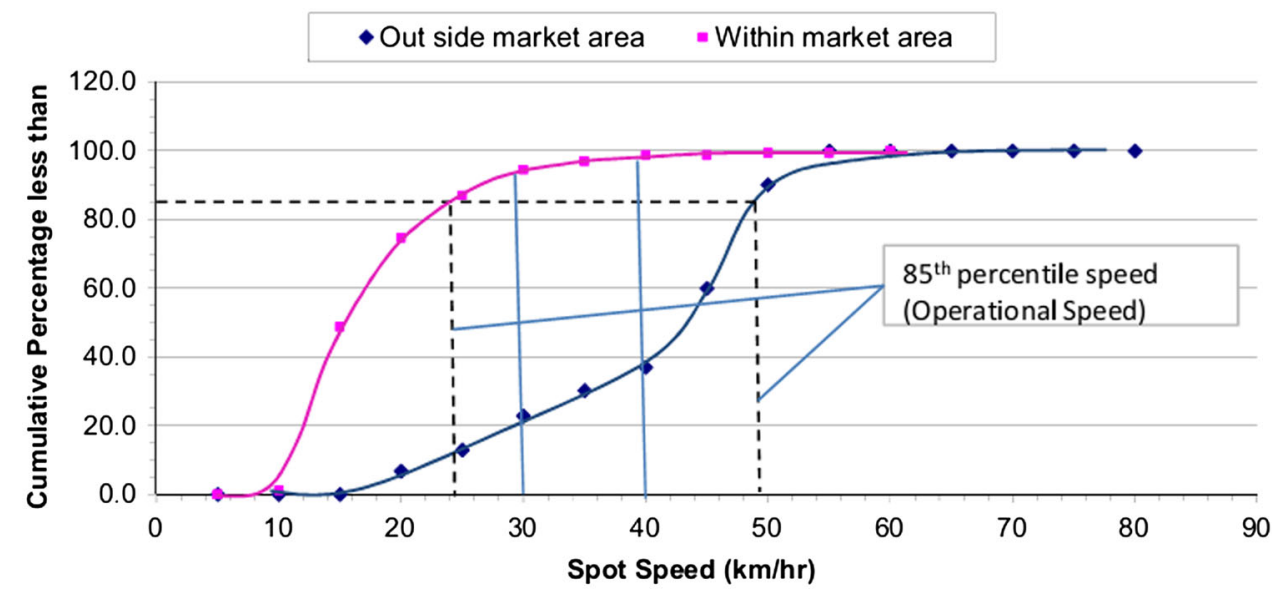

Table 5 Recommended LOS criteria

\begin{tabular}{lll}
\hline LOS & \multicolumn{2}{l}{ Class-II and III 2-lane highway } \\
\cline { 2 - 3 } & $\begin{array}{l}\text { Operational speed }(85 \text { th percentile })(\mathrm{km} / \mathrm{hr}) \\
\text { FFS }=70 \mathrm{~km} / \mathrm{hr}\end{array}$ \\
\hline A & $>65$ & Standard deviation of spot speeds (\%) \\
B & $50-65$ & $8-10$ \\
C & $40-50$ & $5-8$ \\
D & $30-40$ & $3-5$ \\
E & $<30$ & $<3$ \\
\hline
\end{tabular}

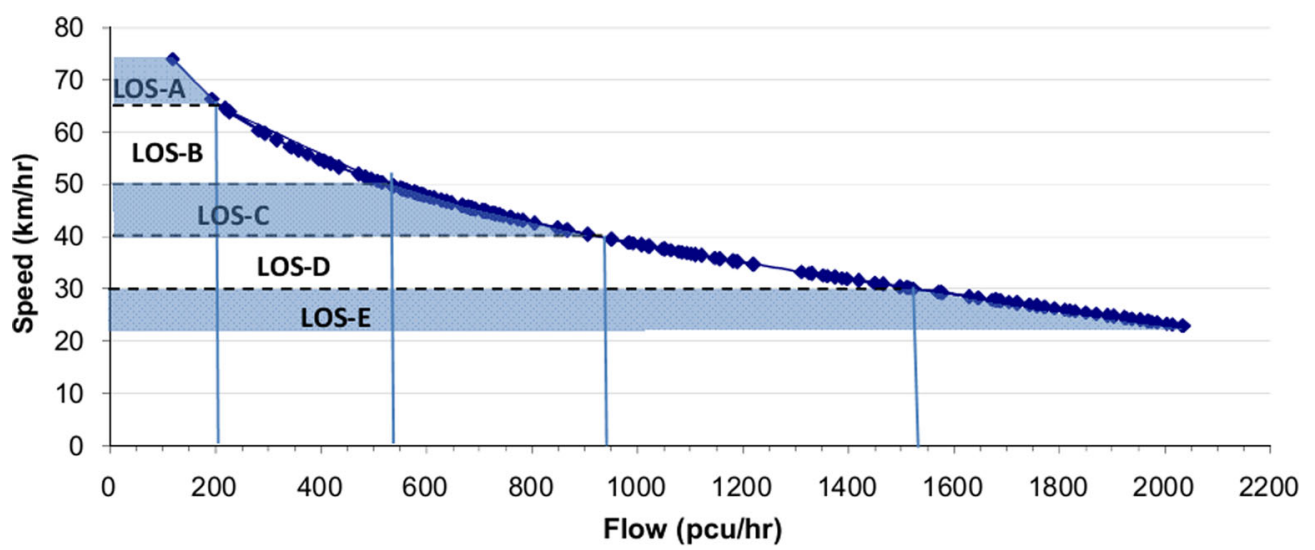

Fig. 13 Prevailing level of service outside the market area 
Fig. 14 Prevailing level of service within market area

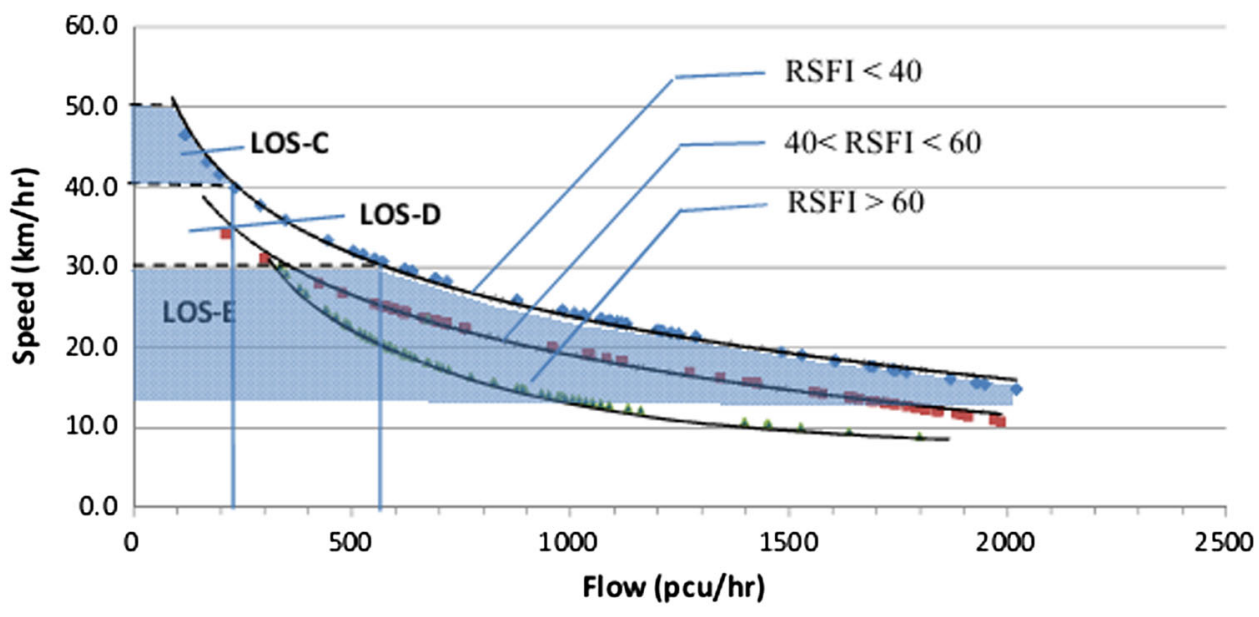

Table 6 Impact of side friction on LOS

\begin{tabular}{|c|c|c|c|c|c|c|c|c|c|}
\hline \multirow[t]{3}{*}{ LOS } & \multirow{3}{*}{$\begin{array}{l}\text { Operational } \\
\text { speed } \\
(\mathrm{km} / \mathrm{hr})\end{array}$} & \multicolumn{2}{|c|}{ Outside market area } & \multicolumn{6}{|c|}{ Within market area } \\
\hline & & \multirow{2}{*}{$\begin{array}{l}\text { Corresponding } \\
\text { traffic volume } \\
(\mathrm{pcu} / \mathrm{hr})\end{array}$} & \multirow{2}{*}{$\begin{array}{l}\text { Standard } \\
\text { deviation of } \\
\text { spot speeds }\end{array}$} & \multicolumn{2}{|c|}{$\begin{array}{l}\text { Side friction is low (RSFI } \\
<40)\end{array}$} & \multicolumn{2}{|c|}{$\begin{array}{l}\text { Side friction is moderate } \\
\text { (RSFI 40-60) }\end{array}$} & \multicolumn{2}{|c|}{$\begin{array}{l}\text { Side friction is severe } \\
(\text { RSFI }>60)\end{array}$} \\
\hline & & & & $\begin{array}{l}\text { Traffic } \\
\text { volume } \\
(\mathrm{pcu} / \mathrm{hr})\end{array}$ & $\begin{array}{l}\text { Standard } \\
\text { deviation of } \\
\text { spot speeds }\end{array}$ & $\begin{array}{l}\text { Traffic } \\
\text { volume } \\
(\mathrm{pcu} / \mathrm{hr})\end{array}$ & $\begin{array}{l}\text { Standard } \\
\text { deviation of } \\
\text { spot speeds }\end{array}$ & $\begin{array}{l}\text { Traffic } \\
\text { volume } \\
(\mathrm{pcu} / \mathrm{hr})\end{array}$ & $\begin{array}{l}\text { Standard } \\
\text { deviation of } \\
\text { spot speeds }\end{array}$ \\
\hline A & $>65$ & $<200$ & 11.4 & - & - & & & & \\
\hline $\mathrm{B}$ & $50-65$ & $200-550$ & & - & - & & & & \\
\hline $\mathrm{C}$ & $40-50$ & $550-950$ & & $<200$ & 8.99 & & & & \\
\hline $\mathrm{D}$ & $30-40$ & $950-1550$ & & $200-550$ & & $200-400$ & 6.27 & & \\
\hline $\mathrm{E}$ & $<30$ & $>1550$ & & $>550$ & & $>400$ & & $>300$ & 6.05 \\
\hline
\end{tabular}

field data collected from three study roads adjacent to Kolkata. This study could be extended for larger road network and variety of road sections and market categories for Indian roads.

Acknowledgments The authors acknowledge the opportunity to present the research work that forms the basis of this article at the 3rd Conference of the Transportation Research Group of India (TRG) held at Kolkata (India) from 17 to 20 December, 2015.

\section{References}

1. Chandra S (2004) Capacity estimation procedure for Two-Lane roads under mixed traffic conditions, Paper No 498. Indian Highways, Indian Roads Congress, New Delhi

2. Anjaneyulu MVLR, Nagaraj BN (2009) Modelling congestion on urban roads using speed profile data, Paper No 549. J Indian Roads Congr

3. Arasan Thamizh V, Reebu Zachariah Koshy (2004) Simulation of heterogeneous traffic to derive capacity and service volume standards for urban roads, Paper No 500. J Indian Roads Congr, p 219
4. Debasis Basu, Maitra SR, Bhargab Maitra (2006) Modelling passenger car equivalency at an urban mid-block using stream speed as measure of equivalence. Eur Transp n 34:75-87

5. Arkatkar SS, Thamizh Arasan V (2012) Micro-simulation study of vehicular interactions on upgrades of intercity roads under heterogeneous traffic conditions in India. Eur Transp Issue 52(3): $1-33$

6. Zhaoyang LU, Qiang MENG (2013) Analysis of traffic speed-density regression models - a case study of two roadway traffic flows in China. In: Proceedings of the Eastern Asia Society for Transportation Studies, vol 9

6. Zhaoyang LU, Qiang MENG (2013) Analysis of traffic speeddensity regression models - a case study of two roadway traffic flows in China. In: Proceedings of the Eastern Asia Society for Transportation Studies, vol 9

7. Dhamaniya A, Chandra S (2013) Concept of stream equivalency factor for heterogeneous traffic on urban arterial roads. J Transp Eng ASCE 139(11):1117-1123

8. IRC (2001) Special Publication No. 19, Manual for survey, investigation and preparation of road project, The Indian Roads Congress, New Delhi

9. IRC-64-1990 (2001) Guidelines for capacity of roads in rural area, The Indian roads congress, New Delhi

10. Highway Capacity Manual (HCM)-2010, USA, vol 2, Chapter 15 